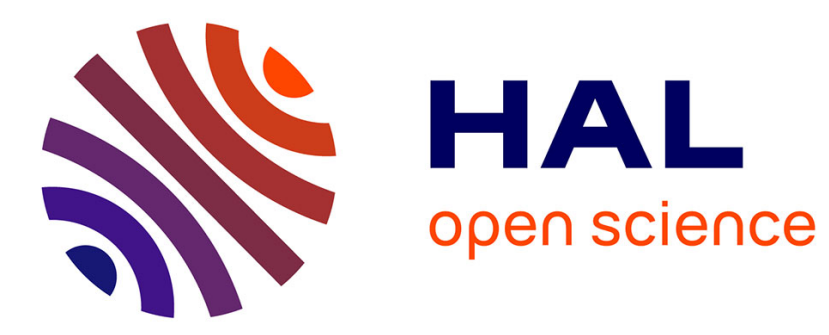

\title{
Fabrication of a Multiple Heater-Sensor Platform for Cell Temperature Monitoring
}

\author{
A. Garraud, Skandar Basrour, D. Peyrade
}

\section{To cite this version:}

A. Garraud, Skandar Basrour, D. Peyrade. Fabrication of a Multiple Heater-Sensor Platform for Cell Temperature Monitoring. DTIP 2020, IEEE, Jun 2020, Conférence virtuelle, France. 10.1109/DTIP51112.2020.9139132 . hal-03022442

HAL Id: hal-03022442

https://hal.univ-grenoble-alpes.fr/hal-03022442

Submitted on 25 Nov 2021

HAL is a multi-disciplinary open access archive for the deposit and dissemination of scientific research documents, whether they are published or not. The documents may come from teaching and research institutions in France or abroad, or from public or private research centers.
L'archive ouverte pluridisciplinaire HAL, est destinée au dépôt et à la diffusion de documents scientifiques de niveau recherche, publiés ou non, émanant des établissements d'enseignement et de recherche français ou étrangers, des laboratoires publics ou privés. 


\section{Fabrication of a Multiple Heater-Sensor Platform for Cell Temperature Monitoring}

\author{
Alexandra Garraud \\ Univ. Grenoble Alpes, CNRS \\ CEA/LETI Minatec, LTM, \\ Grenoble, FRANCE \\ alexandra.garraud@cea.fr
}

\author{
Skandar Basrour \\ Univ. Grenoble Alpes, CNRS, \\ TIMA, \\ Grenoble, FRANCE \\ skandar.basrour@univ-grenoble- \\ alpes.fr
}

\author{
David Peyrade \\ Univ. Grenoble Alpes, CNRS \\ CEA/LETI Minatec, LTM \\ Grenoble, FRANCE \\ david.peyrade@cea.fr
}

\begin{abstract}
In this paper, we present the early-stage development of a transparent device capable of maintaining the temperature of the cells of four parallel cultures. The temperature of the cells is regulated while live imaging the active area. Temperature distribution is first determined through numerical analysis and later, validated by infrared thermography. The four heater-sensor platform is fabricated using microfabrication techniques followed by an electrical characterization. The nominal set of parameters is determined. Lensfree optical imaging is performed while the system is regulating at $37^{\circ} \mathrm{C}$ and $100 \mu \mathrm{m}$ diameter micro particles can be detected on the surface.
\end{abstract}

Keywords- Heater-sensor platform; Transparent microsystem; cell culture device; Lensfree Imaging

\section{INTRODUCTION}

When performing cell culture, maintaining the optimal environmental conditions in terms of temperature, of gas composition and of dimness, is critical to assure the most favorable cellular development $[1,2]$. In recent years, thanks to the breakthrough of microfluidics and bio-MEMS $[3,4]$, more and more devices have been designed to closely monitor the temperature during cell culture [5-8]. Those solutions are still relatively large with an active area in the $\mathrm{mm}^{2}$ range. They are mostly composed of one single heater, and one or more temperature sensors. These heater-sensor systems are designed to apply a desired temperature (heater) while measuring it (sensor). But these systems still require to be brought under an optical microscope to perform imaging and to monitor closely the cell growth. This back-and-forth manipulation could disturb the cells or even induce their premature death. To our knowledge, no system has been developed that offers simultaneously temperature control on a small active area size, close to single cell range, with an integrated live imaging component.

In this paper, we present the conception, the fabrication, and the characterization of a transparent platform, with multiple heater-sensor systems, that offers live imaging capability. Therefore, transparency of the heater-sensor system is key to allow for optical observations of the cells that will be located above. This property will guide the fabrication choices when designing the platform.

Section 2 describes the microfabrication steps necessary to realize a thermally-regulated cell culture platform. The architecture of the heater has been designed and validated by numerical modeling and is presented in Section 3. Three types of characterization are performed to test the multiple heatersensor platform. First, the nominal current to inject in the heater to reach $37^{\circ} \mathrm{C}$, most usual temperature to reach for cell culture, is found in a two-step electrical characterization

(Section 4). Second, an infrared thermal imaging step characterizes the thermal homogeneity (Section 5). Last, the optical characterization proves that live imaging is possible with this platform (Section 6). Conclusions and perspectives for the future are found in Section 7.

\section{MICROFABRICATION}

Transparency and precise temperature regulation are both decisive to conceive a cell-culture-friendly platform. Therefore, a transparent conductive oxide indium tin oxide (ITO) is chosen as the resistive heating element. On the other hand, platinum, due to its high temperature sensitivity, is selected as the sensing material of the resistive temperature detector (RTD). Finally, silicon nitride is selected as it allows the heat flux to move from the ITO heater to the Pt sensor while avoiding any short between the two layers.

Substrate is a rectangular ITO-coated glass slab (SigmaAldrich), whose dimensions are $75 \mathrm{~mm} \times 25 \mathrm{~mm} \times 1.1 \mathrm{~mm}$. The selected sheet resistivity is $15-25 \Omega /$ sq, with a thickness of $105 \mathrm{~nm}$. The five successive layers are patterned using a maskless photolithography tool (SmartPrint, Microlight3D). The microfabrication steps are described in Fig 1. After a cleaning step, ion beam etching is used to pattern the ITO thin film (MU400, Plassys). The SiNx interlayer is deposited by PVD (CT100, Alliance Concept) with twice the thickness of the ITO layer to ensure good coverage. The $\mathrm{Pt}$ layer is deposited with a metal evaporator (MEB550, Plassys), using a $10 \mathrm{~nm}$ thick titanium adhesion layer. A $200 \mathrm{~nm}$ thick SiNx protective layer is finally deposited over the entire platform to prevent any electrical short when growing cells.

1.

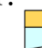

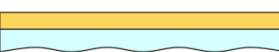

2.

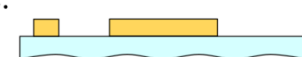

3.

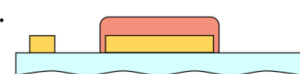

4.

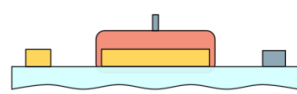

5.

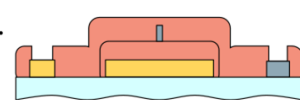

6.

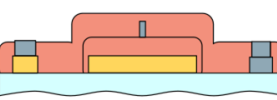

Glass
ITO-coated glass slab

ITO etch $(105 \mathrm{~nm})$

Heater

SiNx PVD deposition $(200 \mathrm{~nm})$

Interlayer

Ti/Pt evaporation $(75 \mathrm{~nm})$

Sensor

SiNx PVD deposition $(200 \mathrm{~nm})$

Protective layer

$\mathrm{Ti} / \mathrm{Pt}$ evaporation $(75 \mathrm{~nm})$

Electric pads 
Fig 2 presents a picture of the platform with the four heater-sensor microsystems along with a close-view of the active area where the temperature should be as uniform as possible.

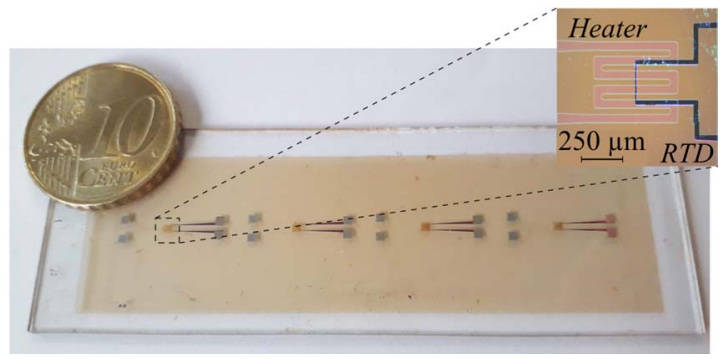

Fig 2. Picture of the platform with four heater-sensor microsystems. Inset: Microscope image of the active area.

\section{NUMERICAL MODELING}

An initial version of the heater pattern has been designed as a 5-branch meander heater, with $25-\mu \mathrm{m}$ wide tracks in the active area [8]. It was supposed to ensure a larger coverage and supposedly a more homogeneous temperature uniformity. ANSYS FEM (v17) has been used to model the temperature distribution, as presented in Fig 3. As expected, the hot region is centered in the active area (dimensions: $500 \mu \mathrm{m} \times 500 \mu \mathrm{m}$ ). However, resulting electrical resistance induced a voltage too large to reach $37^{\circ} \mathrm{C}(62 \mathrm{~V})$, that could have endangered the cells above.

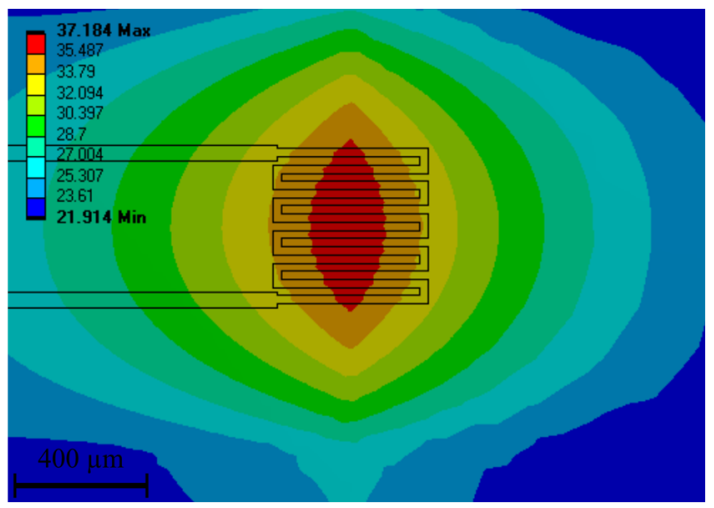

Fig 3. Temperature distribution when the ITO heater is normally activated (5-branch meander design).

Therefore, a second design is introduced in this paper, with a 3-branch meander and wider tracks that decreases drastically the electrical resistance, while having a similar temperature uniformity. Temperature distribution is presented in Fig 4 for this configuration: the highest temperatures are found in the active area.

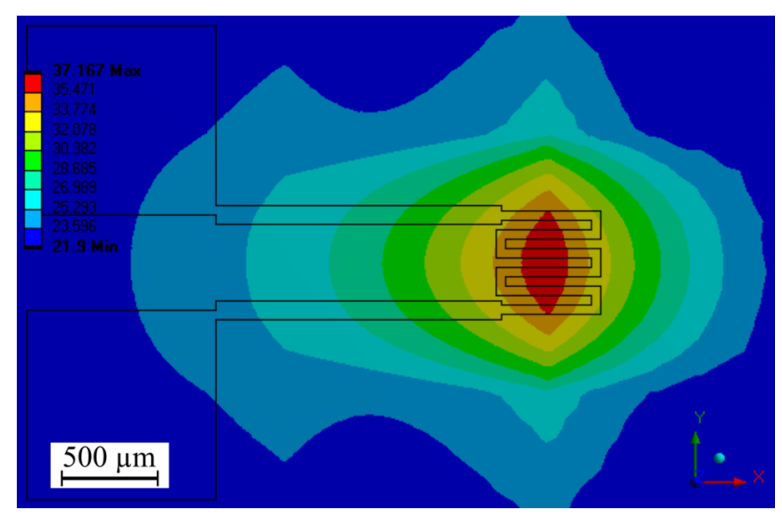

Fig 4. Temperature distribution when the ITO heater is normally activated (3-branch meander design).
The temperature profiles over the active area $(500 \mu \mathrm{m} \times$ $500 \mu \mathrm{m})$ in the three directions are shown in Fig 5. The axis origin is taken as the center of the active area. The 36 to $37^{\circ} \mathrm{C}$ region is emphasized by the dotted-dashed line. In the $\mathrm{x}$ direction, it expands a little less than $100 \mu \mathrm{m}$ on both sides. In the y-direction, this region is twice as large. The z-axis thermal decrease to $36^{\circ} \mathrm{C}$ reaches $70 \mu \mathrm{m}$, high enough to grow one layer of cells.
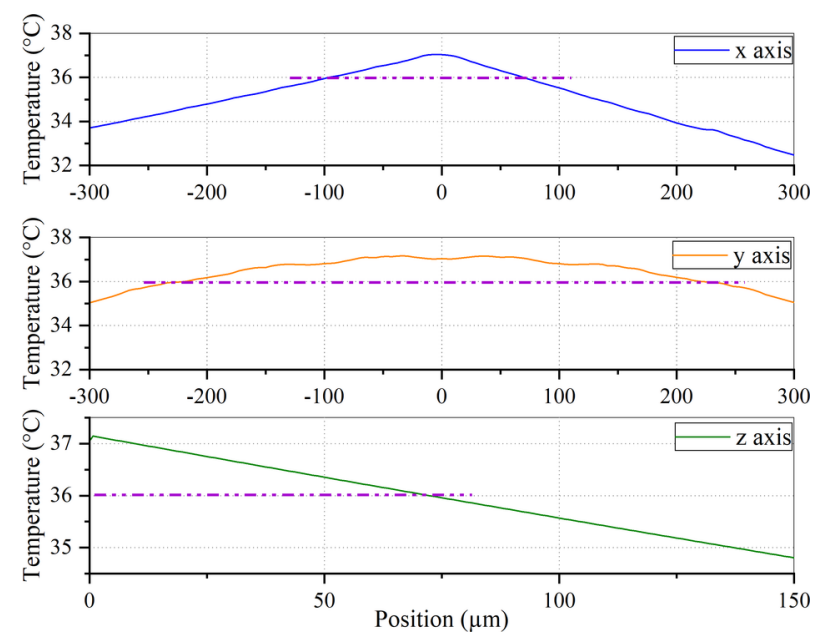

Fig 5. Numerical results of temperature profiles along the $\mathrm{x}-, \mathrm{y}$ - and $\mathrm{z}$-axes in the active area.

\section{ELECTRICAL CHARACTERIZATION}

To determine the nominal current to inject in the heater, the relationship between the Pt resistance and the surrounding temperature sensor needs to be first characterized. Then the current vs. temperature behavior can be determined.

\section{1) Temperature Sensor Characterization}

Once the device is fabricated, the Pt resistance $[\mathrm{R}(\mathrm{T})=$ $\left.\mathrm{R}_{0}(\alpha \mathrm{T}+1)\right]$ is measured in a temperature-controlled oven (UFP 400 , Memmert) to obtain $\alpha$, the temperature coefficient of resistance and $\mathrm{R}_{0}$, the resistance at $0{ }^{\circ} \mathrm{C}$. The resistance is measured with a Keysight B2901A sourcemeter by injecting a $50 \mu \mathrm{A}$ current and measuring the resulting voltage. Four different temperatures are selected for the $\mathrm{Pt}$ resistance calibration, spanning across the $37^{\circ} \mathrm{C}$ temperature, as shown in Fig 6. A linear fit is found, with $\alpha=2462 \mathrm{ppm}^{\circ} \mathrm{C}^{-1}$, in accordance with the literature.

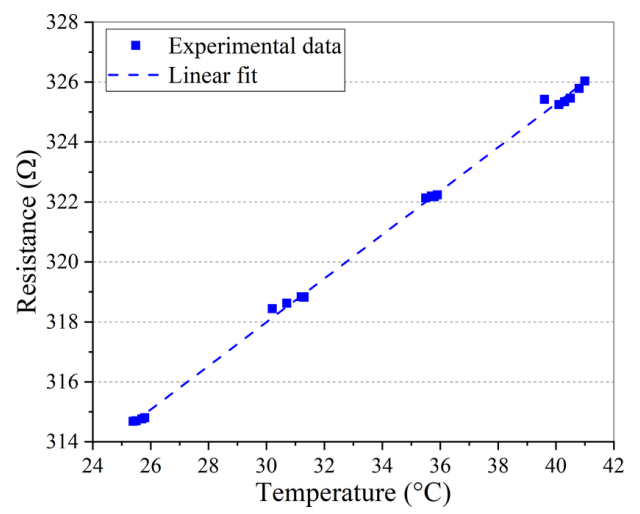

Fig 6. Pt resistance versus device temperature, depending on the ITO sheet resistivity.

\section{2) Current vs. Temperature Behavior}

ITO heater is then characterized by injecting a known current while measuring the $\mathrm{Pt}$ resistance, resulting in the temperature determination. ITO current is controlled by a 
Keithley 2400 sourcemeter while measuring the Pt resistance with a Keysight B2901A sourcemeter (50 $\mu$ A current). Fig 7 presents the experimental data along with a quadratic fit. We determine that an $82 \mathrm{~mW}$ power dissipation is necessary to reach a temperature of $37^{\circ} \mathrm{C}$, corresponding to a current of $6 \mathrm{~mA}$.

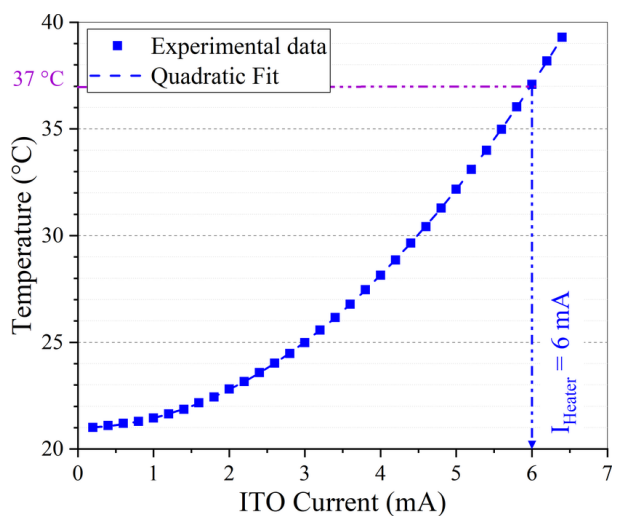

Fig 7. Pt resistance temperature versus ITO current, depending on the ITO sheet resistivity.

\section{INFRARED THERMOGRAPHY}

\section{A. Lock in Thermography}

Lock in Thermography consists of an emissivity map of the device surface when the heater is activated. A Keithley $2611 \mathrm{~A}$ pulsed current source injects a $1.5 \mathrm{~mA}$ current into the ITO heater and the resulting infrared (IR) qualitative image is obtained. Results are shown in Fig 8. Note that this study was conducted on the 5-branch meander configuration.

Because of a difference in emissivity between the ITO and the $\mathrm{Pt}$, comparative discussion focuses only on the ITO tracks. One can see that the hot region is only located in the active region and that the contact pads do not heat. This result agrees with the numerical modeling prediction.

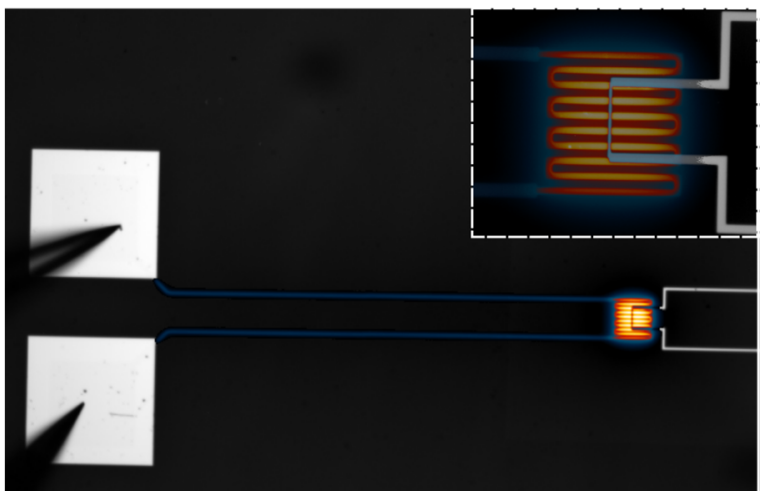

Fig 8. Lock in Thermography of a heater-sensor microsystem, (x1 objective). Inset: Zoom-in view on the active area (x10 objective).

\section{B. Quantitative IR Thermography}

Quantitative thermography requires a calibration step to measure the absolute temperature. The device to characterize is placed on a temperature-regulated chuck into an isolated chamber. First, an emissivity map is taken when all is thermalized at $25^{\circ} \mathrm{C}$. Temperature is then risen to $45^{\circ} \mathrm{C}$, and when stabilized, a second emissivity map is recorded. A pixelby-pixel linear regression of the emissivity behavior is obtained and is used to extract temperature. Chuck temperature is then finally decreased to $25^{\circ} \mathrm{C}$ for the IR thermography to start.
Current is gradually increased in the ITO heater, and a picture is recorded at each step. Fig 9 presents the IR thermography when the nominal current $\mathrm{I}=1.6 \mathrm{~mA}$ is injected into the 5-branch meander heater. The temperature distribution validates the numerical modeling results. Unfortunately, slight vibrations of the equipment moved the sample slightly $(\sim 40 \mu \mathrm{m}$ in the y-direction) and led to temperature misrepresentation, especially for the Pt sensor.

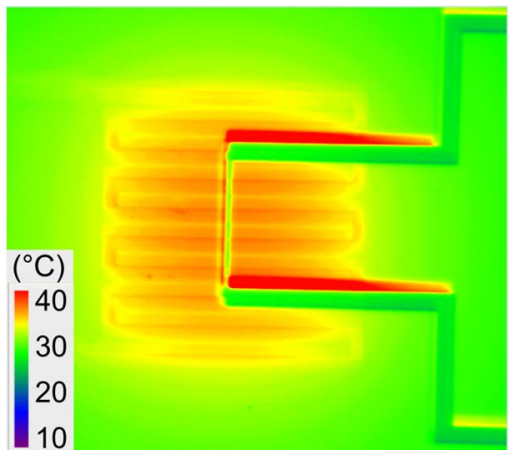

Fig 9. IR thermography of the active area (Nominal current: $\mathrm{I}=1.6 \mathrm{~mA}$, 5-branch meander configuration, 10x objective).

\section{LENSFREE IMAGING CHARACTERIZATION}

Having confirmed that the temperature distribution is what we expected, we move to having an additional function to the cell-culture platform with the live-imaging capability. This technique allows for more optical data, leading to a better understanding of the cellular processes [9]. Only a very few biosystems offer thermal regulation while observing, and those found still seem to be at the mesoscale [10]. Here we perform live imaging by using a commercial lensfree CMOS imager. Image acquisitions are recorded with a Cytonote $1 \mathrm{~W}$ system (iPRASENSE, Montpellier, France). We have chosen to image micro particles based on polystyrene (PS) $(100 \mu \mathrm{m}$ diameter, $5 \%$ concentration, dark blue, Sigma Aldrich) to validate the bifunctional platform. Diameter is chosen to mimic cells that will be grown on the active area.

The experiment is conducted as follow: $0.2 \mu \mathrm{L}$ of the PS particles solution is dispensed over the active area while injecting the nominal set of currents in the heater-sensor microsystem (Fig 10). The same instrumentation as in the electrical characterization is used. The CMOS sensor is in contact with the glass slab bottom side, leading to a working distance of about $1.1 \mathrm{~mm}$ to image the top side of the active area. No reconstruction is used for when acquiring an image.

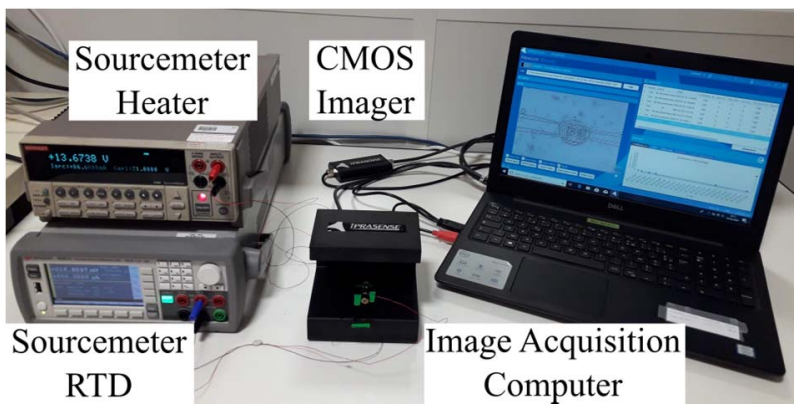

Fig 10. Picture showing the experimental setup to live image while regulating the temperature.

Fig 11.a) shows an optical microscope image of the active area having six PS blue particles, five over the top branch of the Pt track, and one on the bottom one. Only the Pt film and the SiNx interlayer can be seen on this visible light image. Fig 11.b) presents the same configuration, with the lensfree 
imaging setup. On this frame, the ITO heater tracks can be observed as well. While the heater-sensor system is visible, it does not prevent from imaging all six particles, demonstrating that the platform is transparent enough to observe cells of a similar diameter in the future.

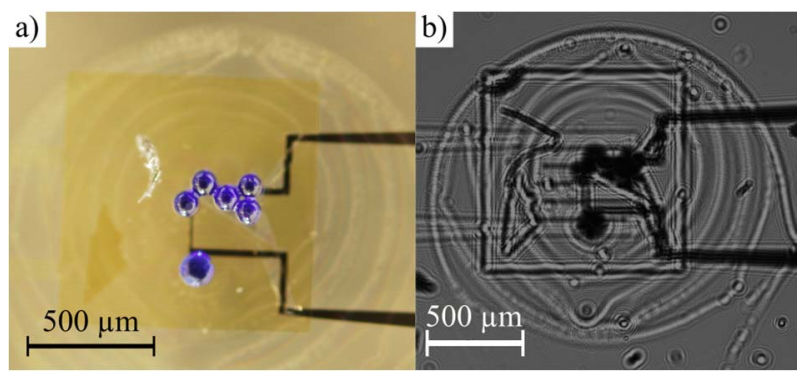

Fig 11. a) Optical microscope image of the active area, showing six PS particles on the surface; b) Lensfree image of the same active area as a) obtained while regulating the temperature (no image reconstruction).

\section{CONCLUSIONS}

The multiple heater-sensor microsystems that is introduced here is capable of regulating, i.e. heating and measuring, the temperature of an active area at $37^{\circ} \mathrm{C}$. Temperature rise is localized in the active area. Temperature uniformity has been first modeled through numerical analysis and validated by IR thermography. Electrical characterization has been carried out to determine the nominal current to inject into the heater to reach the cell-friendly temperature.

Lastly, we demonstrate that the active area can be imaged in real time using a lensfree imaging system while regulating the temperature. PS particles have been used so far but future development will involve cells.

This bifunctional capability is a steppingstone towards developing a fully integrated solution that will incorporate a CMOS imager with a thermal regulation component. A future development will also involve a microfluidic stage to allow for perfusion.

\section{ACKNOWLEDGMENT}

The authors would like to thank the technical staff of PTA, Upstream Technological Platform, for their assistance during the microfabrication process. The authors thanks Gaëtan Debontride (CIME Nanotech) for his assistance during the electrical characterization. The authors thanks Denis Blachier (CEA LETI) for his assistance during the thermal imaging process.

\section{REFERENCES}

[1] Mckenna N M and Wang Y-L 1988 Chapter 12. Culturing Cells on the Microscope Stage Fluorescence Microscopy of Living Cells in Culture Part A. Fluorescent Analogs, Labeling Cells, and Basic Microscopy (Methods in Cell Biology) pp 195-205

[2] Tehranirokh M, Kouzani A Z, Francis P S and Kanwar J R 2013 Microfluidic devices for cell cultivation and proliferation Biomicrofluidics 7051502

[3] Ni M, Tong W H, Choudhury D, Rahim N A A, Iliescu C and Yu H 2009 Cell culture on MEMS platforms: A review Int. J. Mol. Sci. 10 5411-41

[4] Pasirayi G, Auger V, M. Scott S, K.S.M. Rahman P, Islam M, O’Hare L and Ali Z 2011 Microfluidic Bioreactors for Cell Culturing: A Review Micro Nanosyst. 3 137-60

[5] Streit P, Nestler J, Shaporin A, Graunitz J and Otto T 2018 Design methodology and results evaluation of a heating functionality in modular lab-on-chip systems J. Micromechanics Microengineering 28 064001

[6] Lei Z, Xie D, Mbogba M K, Chen Z, Tian C, Xu L and Zhao G 2019 A microfluidic platform with cell-scale precise temperature control for simultaneous investigation of the osmotic responses of multiple oocytes Lab Chip

[7] Peng J, Fang C, Ren S, Pan J, Jia Y, Shu Z and Gao D 2019 Development of a microfluidic device with precise on-chip temperature control by integrated cooling and heating components for single cell-based analysis Int. J. Heat Mass Transf. 130 660-7

[8] Garraud A, Debontride G, Blachier D, Basrour S and Peyrade D 2019 Multiple Heater-Sensor Microsystems on a Single Glass Slide to Monitor Cell Culture Temperature JNTE 2019 (Grenoble)

[9] Cole R 2014 Live-cell imaging - The cell's perspective Cell Adh. Migr. 8 452-9

[10] Kriesi C, Steinert M, Marmaras A, Danzer C, Meskenaite V and Kurtcuoglu V 2019 Integrated Flow Chamber System for Live Cell Microscopy Front. Bioeng. Biotechnol. 7 